\title{
MIDAS
}

Museus e estudos interdisciplinares

$11 \mid 2020$

Dossier temático: "Perspetivas sobre o museu eclético"

\section{Maria João Vilhena de Carvalho - A Constituição de uma Coleção Nacional. As Esculturas de Ernesto Vilhena}

\section{Vera Mariz}

\section{OpenEdition}

\section{Journals}

Edição electrónica

URL: http://journals.openedition.org/midas/1614

DOI: $10.4000 /$ midas. 1614

ISSN: 2182-9543

\section{Editora:}

Alice Semedo, Paulo Simões Rodrigues, Pedro Casaleiro, Raquel Henriques da Silva, Ana Carvalho

\section{Refêrencia eletrónica}

Vera Mariz, "Maria João Vilhena de Carvalho - A Constituição de uma Coleção Nacional. As Esculturas de Ernesto Vilhena », MIDAS [Online], 11 | 2020, posto online no dia 19 novembro 2020, consultado no dia 21 novembro 2020. URL : http://journals.openedition.org/midas/1614 ; DOI : https://doi.org/ $10.4000 /$ midas. 1614

Este documento foi criado de forma automática no dia 21 novembro 2020

\section{(i) $\$(9)$

Midas is licensed under a Creative Commons Attribution-NonCommercial-ShareAlike 3.0 International License 


\title{
Maria João Vilhena de Carvalho - A Constituição de uma Coleção Nacional. As Esculturas de Ernesto Vilhena
}

\author{
Vera Mariz
}

\section{REFERÊNCIA}

Carvalho, Maria João Vilhena de. 2017. A Constituição de uma Coleção Nacional. As Esculturas de Ernesto Vilhena. Vol. 10. Coleção Estudos de Museus. Casal de Cambra: Caleidoscópio e Direção-Geral do Património Cultural. 486 páginas, ISBN:

978-989-658-503-7.

1 A obra em análise resultou da tese de doutoramento em História da Arte apresentada por Maria João Vilhena de Carvalho, no ano de 2014, à Faculdade de Ciências Sociais e Humanas da Universidade Nova de Lisboa. ${ }^{1}$ A publicação, datada de 2017, enquadra-se na Colecção Estudos de Museus, uma iniciativa que tem permitido uma imprescindível divulgação de estudos avançados nas áreas dos museus e da museologia.

2 Em linhas gerais, estamos perante uma obra de fôlego que atesta a importância crescentemente reconhecida - da realização de investigações de fundo na área do coleccionismo e do mercado de arte das primeiras décadas de Novecentos. Afinal, ao apresentar um trabalho de grande rigor que demonstra a relevância de Ernesto de Vilhena enquanto coleccionador, esta obra evidencia, também, a falta de mais investigações que permitam enquadrar e avaliar este e outros casos.

o principal intento da autora terá sido ampliar o conhecimento acerca da colecção de escultura reunida por Ernesto de Vilhena e do seu perfil de coleccionador de arte. Todavia, notamos a inexistência de uma introdução, bem como de uma conclusão, que nos parecem fundamentais para uma rápida aproximação do leitor a esta aspiração e restantes contornos caracterizadores do estudo. Salvo este aspecto, trata-se de um trabalho bem estruturado constituído por três grandes capítulos: I) «Ernesto Jardim de 
Vilhena: A Formação do Colecionador»; II) «A Coleção Vilhena. Arquitetura de uma Coleção Nacional de Escultura»; III) «Do Privado ao Público. A Coleção de Escultura de Ernesto Vilhena no Museu Nacional de Arte Antiga».

4 De resto, saliente-se desde já o recurso sistemático e criterioso a um extenso e variado elenco de fontes primárias e secundárias, bem como de bibliografia, aspectos evidentes no ineditismo de grande parte da narrativa.

5 O primeiro capítulo corresponde a uma biografia exaustiva de uma figura que, não obstante a sua importância no contexto económico e cultural da época, carecia de um estudo dirigido e aprofundado. Apesar deste primeiro capítulo e, em particular, a questão genealógica da família Jardim de Vilhena nos parecer, em determinados momentos, excessivamente densa, é neste momento que encontramos aspectos fundamentais para a formação do perfil do coleccionador. Neste âmbito, será particularmente relevante a relação com o avô materno, Manuel Pereira Jardim, director do Gabinete de Mineralogia, Geologia e Paleontologia do Museu de História Natural da Universidade de Coimbra. Trata-se de uma circunstância que permitiu a Vilhena conviver desde cedo com colecções, ainda que de mineralia e naturalia, com princípios científicos de organização das mesmas e com o "valor cívico de responsabilidade pelo património" (p. 35).

6 Paralelamente, destaque-se a amizade travada na infância com Reynaldo dos Santos e as suas "aventuras arqueológicas" (p. 36) na Figueira da Foz, momentos que atestam, como a autora prova, o facto dos vínculos geográficos da juventude de Vilhena se revestirem da maior relevância para a definição do seu perfil de coleccionador, correspondendo a futuros locais de visita e aquisição de obras de arte.

7 Por fim, destacamos a localização da residência de família na Rua de S. Bento, artéria onde funcionava o Mercado com as suas bancas de bric-à-braquistas que, como a autora legitimamente propõe, poderão ter exercido uma influência decisiva. Esta hipótese afigura-se-nos particularmente válida se considerarmos que além daquele espaço, esta área era animada por uma série de bazares de antiguidades, caso do Bazar Catholico (futura Leiria \& Nascimento).

8 Após dissertar, ainda no primeiro capítulo, acerca do fulgurante percurso de Vilhena nos territórios coloniais, primeiro como comandante de Marinha e depois como administrador da Diamang, actividade que lhe permitiu reunir a fortuna sem a qual dificilmente lograria construir a sua notável colecção, a autora inaugura o segundo capítulo. Um dos méritos mais importantes desta publicação revela-se neste momento, correspondendo a uma competente análise da construção da colecção Vilhena e, em concreto, à forma eficaz como se articula o perfil do coleccionador e o seu modus operandi com a caracterização do acervo e seus (des)caminhos.

9 Neste âmbito, começa por salientar-se que apesar da voracidade com que Vilhena coleccionou obras de arte e livros, a sua actuação ficou invariavelmente marcada por uma metodologia muito vincada em termos da especificação dos objectos a coleccionar, formas de aquisição e integração das obras no acervo. Subjacente a esta actuação estaria, conforme se demonstra, a vontade de constituir uma colecção de arte representativa da identidade nacional, um inequívoco reflexo da cultura e mentalidade da época mas, também, da herança familiar, formação e actividade laboral do coleccionador. Para alcançar este desiderato, à semelhança do que pratica profissionalmente, Vilhena irá constituir e liderar, entre meados dos anos 1920 e 1967, uma "empresa colecionista familiar" (p. 175), dedicando-se, de forma sistemática e a 
par de parcas iniciativas institucionais - como a realização do Inventário Artístico de Portugal da Academia Nacional de Belas Artes - à prospecção, levantamento, aquisição, conservação e divulgação de um património artístico nacional cronicamente fustigado por actos de incúria, destruição e espoliação. Para tal, irá recorrer a uma extraordinariamente ampla teia de agentes, entre os quais se destaca António Saraiva Nunes, e a uma multiplicidade de formas de aquisição.

Relativamente à teia de relações, tanto em termos de agentes intermediários, restauradores ou especialistas, importa destacar o facto de a autora desvendar e reconstituir uma realidade (ainda) pouco conhecida, revelando um conjunto apreciável de figuras largamente ignoradas pelos estudos acerca do mercado de arte em Portugal. Além da necessidade de aprofundar o conhecimento acerca destes e outros casos carentes de identificação, importará, também, reflectir sobre as ligações entre os diferentes protagonistas e colecções. Senão, note-se como José de Azeredo Perdigão é reconhecido nesta obra enquanto advogado da Diamang, portanto figura próxima de Vilhena mas foi, também, absolutamente determinante, como se sabe, no processo do estabelecimento, em Portugal, da fundação e colecção de Calouste Sarkis Gulbenkian.

11 Sendo legítimo questionar se, face à natureza privada desta iniciativa e à frequente aquisição de peças cuja fruição era legal e tradicionalmente pública, estamos perante actos de esbulho ou de salvaguarda patrimonial, a autora frisa que "o móbil da coleção foi um ato de resgate da memória nacional” (p. 155). A este propósito não se descura o contexto histórico, político ou cultural em que decorre a construção desta colecção, expondo a forma eticamente discutível como os agentes intermediários beneficiaram do ambiente pós Lei da Separação (1911) ou Concordata (1940) e dos seus efeitos para o património, revelando-se o aproveitamento da necessidade/interesse de Juntas de Paróquia, sacristãos, párocos ou bispos alienarem obras de arte sacra.

12 Não obstante o tema primordial desta obra ser a colecção de escultura, os restantes núcleos da colecção Vilhena - cerâmica, têxteis, marfins, prata, mobiliário, azulejo, vidros, pintura, etc. - não só são identificados, como são cuidadosamente analisados, evidenciando, por um lado, a importância daquele acervo e contribuindo, por outro, para um retrato mais fidedigno do coleccionador.

Sucede-se uma atenta análise da colecção de escultura de uma figura que, face às práticas coleccionísticas da época, "não seguiu a moda (...) criou-a ele próprio" (p. 239), reunindo um acervo ecléctico que, ainda assim, atesta uma preferência pelo sentido icónico da escultura, pela criação em pedra e pela produção portuguesa. O local de reunião, organização e exposição da colecção, a residência da Rua de S. Bento, merece um ponto próprio, uma decisão pertinente face à forma como foi adaptada para funcionar como museu privado mas, também, devido à sua relevância enquanto testemunho do perfil de um coleccionador interessado na divulgação pública do seu acervo, fosse esta circunscrita aos círculos sociais e profissionais em que se movia, ou totalmente abrangente, por via de empréstimos a exposições.

O último ponto deste capítulo central, referente ao processo de doação da colecção de escultura, promove a transição para a derradeira fase da obra. Na ausência de um testamento ou de outras determinações acerca do futuro da colecção, tratando-se, afinal, de propriedade da dita "empresa familiar" (p. 248), teria início, ainda no ano da morte do coleccionador (1967), um processo de inventário realizado por uma equipa liderada por Maria José de Mendonça, à época directora do Museu Nacional de Arte Antiga (MNAA). Tratar-se-ia, como se demonstra, de uma medida fundamental 
enquanto primeira fase de um possível arrolamento pelo Estado, à data o único instrumento legal de protecção de património móvel com valor artístico ou histórico.

15 A implementação destas medidas revelar-se-ia decisiva para a preservação da memória e conhecimento de uma colecção que teria, conforme se expõe, destinos muito distintos, incluindo, além da integração no MNAA ou de vendas a outras instituições artístico-culturais, sucessivas alienações em leilões realizados, sobretudo, pela Leiria \& Nascimento. A este propósito, notamos que, devido ao elevado número de objectos e à celeridade do processo, o primeiro leilão não contou com um catálogo, algo que se verificou, também, na igualmente importante almoeda do recheio do Palácio de Monserrate (1946), venda promovida pela mesma casa, um aspecto que dificulta o estudo destes eventos. Neste sentido, como bem se destaca, os selos colocados nas peças que, ainda hoje, alimentam o mercado, revestem-se da maior utilidade.

Relativamente à doação de parte da colecção de esculturas ao Estado Português e ao seu sequente ingresso no acervo do MNAA, todo o processo é minuciosamente escalpelizado, abordando-se, por exemplo, a discussão em relação a outros possíveis destinos. Particularmente relevante é a identificação e análise do processo de dação de obras de arte num contexto no qual esta figura jurídica não existia mas que, em grande parte devido à agenda política do regime, permitiu que ao invés do pagamento do imposto sucessório devido pelos herdeiros, a colecção revertesse a favor da Nação.

A abrangência do terceiro capítulo ultrapassa em muito o processo de integração da colecção Vilhena no MNAA a partir de 1970, momento marcante pela irrevogável transmutação da identidade (privada) do conjunto mas, também, como se demonstra, por um aumento sem precedentes do acervo escultórico daquela instituição.

o lato alcance deste capítulo é justificado pela meritória valorização da ideia de biografia cultural dos objectos artísticos e da necessidade de considerar, de forma contextualizada, a totalidade das suas vivências, pensando-os, neste caso, em contexto de uma colecção privada e em museu público. Deste modo, enquadra-se a existência e gestão desta colecção em problemáticas relevantes para a sua compreensão, nomeadamente no processo de construção do acervo de Escultura do MNAA desde a sua proto-história; na recorrente discussão em torno da criação de um Museu Nacional de Escultura; nas políticas museográficas e museológicas institucionais, ou nas opiniões de José de Figueiredo e de João Couto; bem como na tradicional falta de capacidade do Estado concorrer com entidades privadas na aquisição de obras de arte.

Após a realização, ainda em 1969, de duas exposições na Biblioteca Nacional, no ano de 1970, as 1490 peças constituintes da dação dariam entrada no MNAA, exigindo-se, então, a sua classificação, registo fotográfico, documentação, estudo, conservação e divulgação. Acerca desta fase analisa-se pormenorizadamente o contributo de Maria José de Mendonça, enquadrando-se a dedicação a este acervo - que de resto viria a suscitar o desenvolvimento de um projecto de redimensionalização e reestruturação das reservas de Escultura - no contexto mais lato do seu interesse por esta tipologia artística.

20 Seguem-se as análises dos contributos de Maria Alice Beaumont e de Sérgio Guimarães de Andrade, um período marcado pela definitiva nacionalização da colecção Vilhena (1980) mas, também, por uma série de mudanças na arquitectura do MNAA que, conforme se demonstra, estariam na origem da primeira grande exposição deste acervo, a mostra Coleccionar. A Coleç̧ão Ernesto de Vilhena, realizada no Palácio Nacional de Mafra (1980). Inaugurar-se-ia deste modo curioso - com uma exposição pública que 
visava proporcionar uma aproximação ao coleccionismo privado - uma nova fase da colecção Vilhena, a da sua divulgação em grande escala, primeiro através do incremento de pedidos de empréstimo temporários/permanentes e, depois, com a sua integração na primeira exposição permanente de escultura portuguesa do museu das Janelas Verdes.

21 Concluímos, salientando a importância desta obra não só para o conhecimento de um caso concreto - e incontornável - de coleccionismo artístico mas, também, para o domínio ainda muito insipiente do mercado de arte em Portugal na primeira metade do século $\mathrm{XX}$, dos seus agentes e dinâmicas, incluindo o interessante fenómeno de transmigração e, como tal, de transmutação de identidade, de objectos artísticos de universos públicos para privados e daí, novamente, para a esfera pública.

\section{NOTAS}

1. A autora escreve de acordo com a antiga ortografia.

O trabalho do qual resulta esta recensão está integrado na investigação de pós-doutoramento em curso com o apoio da Fundação para a Ciência e a Tecnologia (FC), através da bolsa SFRH/BPD/ 116050/2016 financiada por verbas do Orçamento de Estado do Ministério da Ciência, Tecnologia e Ensino Superior e Fundo Social Europeu.

\section{AUTORES}

\section{VERA MARIZ}

ARTIS - Instituto de História da Arte da Faculdade de Letras da Universidade de Lisboa, Portugal, vera.mariz@letras.ulisboa.pt 